\title{
Resistencia antimicrobiana en aislados fecales de Escherichia coli procedentes de Cebus yuracus en Napo-Ecuador
}

\author{
Haro León, Nathalí ${ }^{\star *}$; Koch Kaiser, Alma ${ }^{1}$; Carrillo-Bilbao, Gabriel ${ }^{2,3}$ y Martin-Solano, Sarah ${ }^{1,2,4}$ \\ 1 Universidad de las Fuerzas Armadas ESPE, Departamento de Ciencias de la Vida y de la Agricultura, Sangolquí, Ecuador. \\ 2 Universidad Central del Ecuador, Instituto de Investigación en Salud Pública y Zoonosis, Quito, Ecuador. \\ ${ }^{3}$ Universidad Central del Ecuador, Carrera de Ciencias Naturales y del Ambiente, Biología y Química, Quito, Ecuador. \\ ${ }^{4}$ Unité de Biologie du Comportement, Université de Liège, Département des Sciences et Gestion de l’Environnement,
} Liège, Belgium.

e-mail: nathis.caro@gmail.com

Palabras clave: Escherichia coli, primates no humanos, resistencia antimicrobiana.

INTRODUCCIÓN: Escherichia coli es una bacteria comensal típica en el intestino de los animales, aunque también existen sus formas patógenas, $\mathrm{y}$ es considerada un microorganismo centinela para monitorear la evolución de la resistencia antimicrobiana en diferentes ecosistemas. [1] Aunque no se espera que los animales silvestres hayan sido expuestos a antibióticos, se ha evidenciado una creciente prevalencia de resistencia antimicrobiana en la vida silvestre y el medio ambiente. Cebus yuracus es un primate neotropical que habita el noroeste de América del Sur, [2] y su estado de conservación es de preocupación menor según la Lista Roja de Especias Amenazadas de la UICN. Se trata del primer estudio de resistencia a antibióticos en este grupo de primates no humanos.

OBJETIV0: Evaluar el perfil de resistencia a antibióticos en aislados de E. coli procedentes de un grupo de C. yuracus de la parroquia Puerto Misahuallí, Napo-Ecuador.

MATERIALES Y MÉTODOS: El grupo de primates no humanos de estudio constó de 8 individuos (16 muestras) de C. yuracus. Se recolectaron muestras fecales frescas de cada primate, y se aisló e identificó $E$. coli mediante pruebas bioquímicas. Se determinó la susceptibilidad antimicrobiana por el método de difusión con disco.
RESULTADOS: $E$. coli se aisló con una presencia de $81,25 \%$ (13/16), a partir de las muestras fecales obtenidas de C. yuracus. Se encontró resistencia o sensibilidad intermedia a ampicilina $(53,84 \%, 7 / 13)$, oxitetraciclina $(38,46 \%, 5 / 13)$ y sulfametoxazol/trimetoprima $(23,08 \%, 3 / 13)$. Sensibilidad intermedia se identificó a cefuroxima (100\%, 13/13) y ciprofloxacina $(53,85 \%, 7 / 13)$.

CONCLUSIONES: Debido al frecuente contacto de estos primates con moradores y turistas, y a su proximidad al Río Misahuallí, donde se depositan descargas producto de actividades domésticas y económicas, [3] es posible que la resistencia antimicrobiana en este grupo de $C$. yuracus sea de naturaleza antropogénica o por contaminación fecal más que por presiones selectivas, ya que los monos no han sido tratados previamente con antibióticos. Los datos aquí presentados evidencian la importancia de la vigilancia epidemiológica de la resistencia a antibióticos en la vida silvestre debido al potencial de transmisión zoonótica, y constituyen un indicador de la resistencia antimicrobiana en el sitio de estudio.

\section{REFERENCIAS:}

[1] Barreto Â, Guimarães B, Radhouani H, Araújo C, Gonçalves A, Gaspar E, Rodrigues J, Igrejas G, Poeta P. Detection of antibiotic resistant E. coli and Enterococcus spp. in stool of healthy growing children in Portugal. J. Basic Microbiol. 2009; 49(6): 503-512. 
[2] Tirira D. Monos en la Costa. Primates en la Costa de Ecuador. Quito: Editorial Murciélago Blanco y Proyecto PRIMENET. 2007: 13-16.

[3] Tipán Manchado J. Evaluación del impacto ambiental en la desembocadura del río Misahuallí al río Napo, mediante la identificación de macroinvertebrados acuáticos para proponer un plan de manejo ambiental; Loja: Universidad Nacional de Loja. 2016. Disponible en: https://dspace.unl.edu.ec/jspui/ handle/123456789/12315 